\title{
COBERTURA ELEITORAL E VISIBILIDADE DOS CANDIDATOS NO JORNAL GAZETA DO POVO E AS ELEIÇÕES DE 2012 EM CURITIBA
}

\author{
ROMER MOTTINHA SANTOS \\ UNIVERSIDADE FEDERAL DO PARANÁ \\ CURITIBA, PARANÁ, BRASIL \\ E-MAIL: ROMERMOTTINHA@GMAIL.COM
}


COBERTURA ELEITORAL E VISIBILIDADE DOS CANDIDATOS NO JORNAL GAZETA DO POVO E AS ELEIÇÕES DE 2012 EM CURITIBA

Resumo: Este trabalho apresenta os resultados da pesquisa sobre a cobertura eleitoral do jornal Gazeta do Povo sobre as eleições de 2012 em Curitiba. Os dados coletados mostram a visibilidade dos candidatos durante o período eleitoral. A metodologia adotada é quantitativa. Identificou-se que a visibilidade dos candidatos é relacionada com os resultados das pesquisas eleitorais, com isso é estabelecida uma dependência entre as duas variáveis. Palavras chave: Jornal impresso; Cobertura eleitoral; Eleições 2012.

\section{COBERTURA ELECTORAL Y VISIBILIDAD DE LOS CANDIDATOS EN EL PERIÓDICO GAZETA DO POVO Y LAS ELECCIONES DE 2012 EN CURI- TIBA}

Resumen: Este artículo presenta los resultados de la investigación sobre la cobertura de las elecciones do periódico Gazeta Povo en las elecciones de 2012 en Curitiba. Los datos recopilados muestran la visibilidad de los candidatos durante el período electoral. La metodología adoptada es cuantitativa. Se identificó que la visibilidad de los candidatos está relacionada con los resultados de las encuestas, es establece una dependencia entre las dos variables.

Palabras clave: Papel impreso; Cobertura de las elecciones; elecciones de 2012.

ELECTORAL COVERAGE AND VISIBILITY OF THE CANDIDATES IN THE NEWSPAPER GAZETA DO POVO AND ELECTIONS OF 2012 IN CURITIBA

Abstract: This paper presents the results of research on election coverage from the newspaper Gazeta do Povo on elections of 2012 in Curitiba. The data collected show the visibility of candidates during the election period. The adopted methodology is quantitative. It was identified that the visibility of the candidates is related to the results of the polls, it is established a dependency between the two variables.

Keywords: Printed paper; Election coverage; 2012 elections. 


\section{INTRODUÇÃO}

A relação entre a política e a comunicação têm se firmado como um tema relevante dos estudos da atualidade. Compreender os atuais poderes da política e da comunicação, suas mutações e conexões, suas inscrições na sociabilidade contemporânea, passa a ser algo essencial, que orientada por um horizonte democrático e ganha efetividade na crítica da sociedade e na construção de uma sociabilidade mais justa (RUBIM, 2000, p. 7-9).

E a relação entre as eleições e a mídia aparece hoje como um tema dos mais significativos para a compreensão das novas configurações assumidas pela política nos tempos contemporâneos. Para a elucidação desta pertinente temática, uma análise minuciosa do momento eleitoral e uma tentativa de explicitar as ressonâncias da nova circunstância comunicacional e societária sobre o processo eleitoral se faz necessária (RUBIM, 2000, p. 90-91).

As eleições funcionam como procedimento social e fundamental de distribuição do poder de governar, todavia sempre periódico e de caráter momentâneo, pois, a rigor, essa distribuição transcende o episódio eleitoral, ocorrendo no cotidiano por meio da persistente disputa do poder de governar, das condições de governabilidade (RUBIM, 2000, p. 92).

Visto isso, o objetivo deste trabalho é verificar e refletir sobre a cobertura eleitoral do jornal Gazeta do Povo frente às eleições para prefeito de Curitiba em 2012. Os dados aqui apresentados são oriundos da coleta de dados do jornal a partir das suas edições diárias no período eleitoral. Esta pesquisa possibilitou quantificar e comparar o número de matérias publicadas sobre a cobertura eleitoral e em qual período os candidatos tiveram mais visibilidade no jornal. Inicialmente aborda-se a relação entre as eleições e a mídia, com ênfase para o jornal impresso. Nesta parte do texto apresenta-se o referencial teórico para discussão posterior dos dados empíricos. Em seguida expõe-se a metodologia adotada. Logo após apresenta-se o contexto eleitoral em 2012 de Curitiba e os candidatos que disputam a prefeitura, onde os principais nomes são: Gustavo Fruet (PDT), Ratinho Junior (PSC), Luciano Ducci (PSB) e Rafael Greca (PMDB). Posteriormente expõem-se parte dos dados coletados onde é discutida a comparação da visibilidade dos candidatos no jornal com os resultados das pesquisas de intenção de voto.

Este estudo justifica-se pela investigação sobre como os veículos de comunicação informam o público sobre temas pertinentes em períodos específicos. "Quem exercita com responsabilidade a crítica das mídias jornalís- 
Cobertura eleitoral e visibilidade dos candidatos no jornal Gazeta do Povo e as eleições de 2012 em Curitiba

ticas geralmente mira horizontes que, se analisados em perspectiva comparativa, trazem lições importantes" (ROTHBERG, 2011, p. 7).

Na próxima seção apresentamos como referencial teórico algumas abordagens dos autores que debatem a relação da mídia com a política. Neste trabalho discutimos brevemente o conceito de comunicação e política no segundo tópico; na terceira seção apresentamos o contexto eleitoral em Curitiba de 2012, a importância das pesquisas eleitorais e o cenário das pesquisas de intenção de voto em Curitiba; na quarta apresentamos a metodologia adotada; na quinta seção discutimos os resultados do estudo empírico e depois finalizamos com as considerações finais.

\section{MÍDIA E POLÍTICA}

"Pensar a comunicação e o jornalismo em suas conexões com a área da política é um desafio constante para a necessária reflexão sobre o papel fundamental dessa atividade na vida social, como elemento da mais elevada importância para nossa jovem democracia" (SOMMA NETO, 2011, p. 7). Neste aspecto, a relação no jornal impresso da comunicação com a política é apresentada como um amplo tema para pesquisa (QUADROS et al., 2010, p. 2). Os jornais constituem um exemplo da chamada mídia impressa e tem como uma limitação o fato de atingir diretamente um segmento populacional menor do que o rádio e a televisão. Os jornais são prejudicados ainda pela crônica falta de hábito de leitura, comum à maioria dos brasileiros. Outra desvantagem dos jornais com relação à mídia eletrônica é o fato de que a leitura exige atenção do leitor, enquanto que o rádio permite atividades paralelas e a televisão apresenta as informações em blocos objetivos e de curta duração. Todavia, o jornal impresso atinge a classe média, formadora da opinião pública, por ter em seu poder a influência junto às classes que Ihe são imediatamente subordinadas (KUNTZ, 2000, p. 143-144). Os leitores de jornais são mais informados do que os não leitores e, com isso, têm meIhores condições de participar das deliberações cívicas (PUTNAM, 2009, p. 106). Assim, o jornal pode ser definido como um importante agente político e com elevado poder de intervenção no cotidiano político e social do país, pois os periódicos produzem e impõem uma visão particular do campo político, selecionando também o que pode ser publicado ou não (SILVA, 2009, p. 36-37).

A primeira edição da "Pesquisa Brasileira de Mídia" traz um retrato 
representativo e preciso sobre o uso que os brasileiros declaram fazer, atualmente, dos meios de comunicação social (A pesquisa foi realizada em outubro e novembro de 2013 pela Secretaria de Comunicação Social (SECOM) da Presidência da República). Continua sendo predominante a presença da TV nos lares do Brasil, apesar do rápido crescimento da internet. Nada menos que $97 \%$ dos entrevistados afirmaram ver TV, um hábito que une praticamente todos os brasileiros, com independência de gênero, idade, renda, nível educacional ou localização geográfica. A internet e o rádio são meios de comunicação também muito presentes na vida das pessoas, ainda que em menor grau: $61 \%$ têm o costume de ouvir rádio e $47 \%$ têm o hábito de acessar a internet. Já a leitura de jornais e revistas impressos são menos frequentes e alcança, respectivamente, 25\% e 15\% dos entrevistados (SECOM, 2014, p. 7).

Quanto ao jornal impresso a maioria dos brasileiros não costuma consumir esse meio de comunicação: enquanto $75 \%$ dos entrevistados afirmaram não ler jornal, apenas $6 \%$ o fazem todos os dias. Se considerados os respondentes que leem jornal ao menos um dia por semana, o percentual de leitores sobe para $24 \%$. Dessa forma, entre os meios estudados nesta pesquisa, apenas a revista impressa tem uma presença menor que o jornal nos hábitos de consumo de mídia da população brasileira. A frequência de uso do jornal tende a aumentar conforme o foco da análise se desloca dos estratos sociais de menor renda para os de maior renda familiar. O mesmo ocorre quando se observam recortes feitos a partir da escolaridade e do porte do município. Ou seja, quanto maior a renda, a escolaridade ou o porte do município, maior tende a ser a frequência de uso do jornal impresso (SECOM, 2014, p. 64).

Importante observar também que nesta pesquisa, os entrevistados foram interrogados sobre seu nível de confiança nas notícias e publicidades veiculadas por diferentes meios de comunicação: TV, rádio, jornais, revistas, sites, blogs e redes sociais. As informações que apresentam maior nível de confiança são as notícias veiculadas pelos jornais impressos (53\% dos entrevistados que utilizam esse meio dizem confiar sempre ou muitas vezes), seguidos pelas notícias do rádio e da TV, tecnicamente empatadas com 50\% e $49 \%$, respectivamente (SECOM, 2014, p. 82). Ou seja, o jornal impresso é um veículo de comunicação que possui uma credibilidade acima dos demais veículos de comunicação. E este fato torna pertinente para análise os estudos e resultados apresentados nesta pesquisa sobre cobertura eleitoral.

A análise do período eleitoral é pertinente, pois há um compromisso 
Cobertura eleitoral e visibilidade dos candidatos no jornal Gazeta do Povo e as eleições de 2012 em Curitiba

em saber o que os meios de comunicação de massa estão inserindo em debate para a esfera pública. Entende-se que a cobertura tende a apresentar os candidatos envolvidos na disputa pelo poder e suas propostas bem os portos que necessitam de atenção dos políticos para a melhoria do bem-estar dos eleitores (HEDLER; GADINI; CERVI, 2011, p. 80). As eleições impõem-se como pauta pelo próprio calendário pré-definido e cada jornal pode atribuir o espaço aos candidatos e aos temas (ALDÉ; MENDES; FIGUEIREDO, 2007a, p. 3).

As mudanças na cobertura midiática reordenam a consciência das pessoas e os meios de comunicação influenciam a projeção de acontecimentos por meio da opinião pública de modo que "do impacto jornalístico sobre o público advêm condutas passíveis de influência sobre a política” (RODRIGUES, 2002, p. 25). "Na sua seleção diária e apresentação das notícias, os editores e diretores de redação focam nossa atenção e influenciam nossas percepções naqueles que são as mais importantes questões do dia" (McCOMBS, 2009, p. 17-18).

A mídia é quem cria a realidade social. Os fatos chegam aos indivíduos por meio da mídia e são construídos por meio de sua realidade discursiva (RODRIGO ALSINA, 2009, p. 46). A mídia não reflete a sociedade, mas a representa. Nessa representação nem todos os atores sociais recebem o mesmo tratamento jornalístico em qualidade nem em quantidade. Todavia também é necessário considerar que, segundo as características sociopolíticas onde a mídia estiver inserida, serão dadas umas relações diferentes também na produção da notícia. De fato, a mídia, na maior parte das cidades é, conforme as características do sistema, homogênea ou complexa (RODRIGO ALSINA, 2009, p. 65).

\section{METODOLOGIA}

A metodologia utilizada é quantitativa de análise de conteúdo (BABBIE, 2005) que permite testes a fim de observar as relações entre as variáveis em estudo. A pesquisa com uso do método quantitativo seleciona a variável como categoria para descrevê-la em grandes populações, buscando regularidades e generalizações teóricas para determinado universo (LINHARES; ALVES, 2014, p. 29). A análise de conteúdo é somente um método de análise de texto desenvolvido dentro das ciências sociais empíricas. Esta análise de texto faz uma ponte entre um formalismo estatístico e a análise qualitativa 
dos materiais (BAUER, 2003, p. 190).

A planilha de coleta de dados aplicada ao conteúdo diário de jornais consistiu em: quantificar a visibilidade dos candidatos à prefeitura de Curitiba na eleição de 2012 pelo número de citações ou de aparições do nome foto ou imagem dos candidatos no texto de cada matéria, nas edições do jornal impresso Gazeta do Povo. Essa variável possibilita identificar o volume da cobertura eleitoral de cada edição do jornal e a presença nas matérias para cada candidato. Os candidatos selecionados para a coleta da pesquisa foram: Gustavo Fruet (PDT), Ratinho Junior (Carlos Roberto Massa Junior) (PSC), Luciano Ducci (PSB), Rafael Greca (PMDB), Bruno Meirinho (PSOL), Alzimara Bacellar (PPL) e Avanilson Araújo (PSTU). Também avaliamos a valência para a candidato no texto levando em conta seu efeito positivo, negativo, neutro ou equilibrado (DOXA, 2008) para a campanha em questão (sempre que há citação de um candidato).

A manipulação dos dados desta pesquisa foi realizada com o pacote SPSS (Statistical Package for Social Sciences), que é o software mais utilizado em ciências sociais, oferece as possibilidades de cálculo estatístico e informes científicos como: resumir frequências, elaboração de tabelas personalizadas, séries temporais e gráficos (BISQUERRA ALZINA; SARRIERA; MARTÍNEZ, 2004, p. 35-36).

No próximo tópico é apresentado o contexto eleitoral de 2012 em Curitiba, relacionando os candidatos envolvidos na campanha eleitoral para prefeito, a importância das pesquisas eleitorais e os resultados das pesquisas de intenção de voto no decorrer do período eleitoral.

\section{CONTEXTO ELEITORAL DE CURITIBA EM 2012}

Na campanha eleitoral para prefeitura de Curitiba em 2012 a disputa começou acirrada já nas primeiras pesquisas de intenção de voto. Os principais candidatos que concorreram ao cargo de prefeito e que predominaram nas preferências dos eleitores das pesquisas de opinião, foram: Ratinho Junior (PSC), Luciano Ducci (PSB), Gustavo Fruet (PDT) e Rafael Greca (PMDB). Os outros candidatos que também participaram do pleito foram: Bruno Meirinho (PSOL), Alzimara Bacellar (PPL), Avanilson Araújo (PSTU), Carlos Moraes (PRTB) ${ }^{1}$.

1 O Tribunal Regional Eleitoral do Paraná (TRE-PR) indeferiu a candidatura de Carlos Moraes (PRTB) a prefeito de Curitiba (Fonte: Assessoria de Comunicação Social do TRE-PR). Para a coleta de dados desta pesquisa as citações no jornal sobre Carlos Moraes não 
Cobertura eleitoral e visibilidade dos candidatos no jornal Gazeta do Povo e as eleições de 2012 em Curitiba

As pesquisas de opinião na cobertura eleitoral também fazem parte do cenário eleitoral para os profissionais da imprensa. Os principais veículos, normalmente, contratam pesquisas exclusivas, as quais representam um atrativo a mais no produto que fornecem ao público. O mais importante é que elas organizam a visão que os próprios jornalistas têm do processo eleitoral, determinando quais são os candidatos que devem ser levados em conta e quais os movimentos da 'opinião pública' (BIROLI; MIGUEL; MOTA, 2011, p. 68)2.

É importante observar que neste trabalho foram consultadas pesquisas do Datafolha. Instituto de Pesquisas. E o Datafolha foi criado com o objetivo de oferecer conteúdo e servir como ferramenta de planejamento para o jornal Folha de S.Paulo e outros veículos e serviços da empresa. E que boa parte das pesquisas eleitorais de 2012 em Curitiba foram contratadas pela RPC-TV, Rádio CBN - Curitiba e Sociedade Rádio Emissora Paranaense S/A. Todos estes veículos de comunicação fazem parte do Grupo Paranaense de Comunicação - GRPCOM, o qual também faz parte o jornal Gazeta do Povo. Ou seja, as pesquisas eleitorais são importantes para a construção de conteúdo da mídia na cobertura eleitoral, todavia é a própria mídia que solicita e contrata estes serviços. Então a cobertura jornalística e as pesquisas de opinião estão pautadas pela mídia. Para efeitos deste trabalho consideramos preferenciais os resultados das pesquisas de opinião para a construção da notícia, embora seja possível também o contrário, uma análise da construção da notícia com efeitos sobre os resultados das pesquisas de opinião.

A pesquisa realizada nos dias 19 e 20 de julho de 2012, do Datafolha Instituto de Pesquisas, indicou $27 \%$ das intenções de voto para Ratinho Junior, enquanto que Luciano Ducci e Gustavo Fruet ficaram ambos com 23\%, configurando um empate técnico, já Rafael Greca atingiu 10\% das menções. Os outros candidatos foram citados, mas estes não alcançaram $1 \%$ das intenções de voto, fato este que praticamente não se alterou até o final da campanha do primeiro turno.

foram consideradas para este trabalho.

2 Dados de pesquisas eleitorais são, antes de tudo, informações para os eleitores. É perfeitamente lógico que um eleitor pode desistir de seu candidato preferencial em favor de outro com mais chances de vitória, para evitar que um terceiro que ele rejeita vença. Então, as pesquisas são essenciais para esse eleitor. A pesquisa é também sinônimo de consumo de mídia. A utilização de dados de pesquisa nos grandes noticiários (TV, rádio, jornais e revistas) é consequência desse crescente interesse (MENDES, 1991, p. 32). 
Entre os quatro principais candidatos este cenário continuou semeIhante até o final do primeiro turno nas pesquisas de intenção de voto. Conforme a pesquisa realizada pelo Datafolha Instituto de Pesquisas, nos dias 02 e 03 de outubro de 2012, o candidato Ratinho Junior mantinha a liderança com 34\% das intenções de voto, Luciano Ducci tinha 25\%, Gustavo Fruet 18\% e Rafael Greca 10\%. No entanto, os candidatos que avançaram ao segundo turno foram Ratinho Junior e Gustavo Fruet, ao contrário do que indicavam as pesquisas eleitorais ao final do primeiro turno, que apontavam o ex-prefeito Luciano Ducci como adversário de Ratinho Junior. Este cenário se altera no segundo turno com a inversão da liderança nas pequisas de intenção de voto, onde o candidato Gustavo Fruet passou a figurar em primeiro lugar, com 52\% das intenções de voto, a frente de Ratinho Junior, com 36\%, de acordo com a pesquisa realizada pelo Datafolha Instituto de Pesquisas, nos dias 17 e 18 de outubro de 2012.

Então os percentuais de intenção de voto obtidos pelos candidatos no primeiro e no segundo turno foram de $23 \%$, em julho, e $52 \%$, em outubro, para Gustavo Fruet e de $27 \%$, em julho, e $36 \%$, em outubro, para Ratinho Junior. Para fins deste trabalho pressupõe-se que os resultados das pesquisas de intenção de voto podem refletir na visibilidade dos candidatos no jornal. Ou seja, um aumento no percentual de intenção de votos para certo candidato pode representar um aumento da cobertura eleitoral para o mesmo. Essa hipótese possui aderência pelo fato de que em eleições anteriores esta tendência já foi observada (ALDÉ; MENDES; FIGUEIREDO, 2007b, p. 75), como em 2002 e 2006 quando a mídia impressa nacional proporcionou maior visibilidade aos candidatos à frente nas pesquisas à presidência.

\section{A VISIBILIDADE DOS CANDIDATOS NA GAZETA DO POVO}

A cobertura eleitoral apresentada nesta pesquisa foi realizada sobre a Gazeta do Povo, que é o jornal impresso de maior circulação do Estado ${ }^{3}$. O acompanhamento foi durante o período eleitoral do dia $1^{\circ}$ de julho ao dia 31 de outubro de $2012^{4}$. O objetivo principal desta pesquisa é identificar como

3 De acordo com a Associação Nacional de Jornais (ANJ) a Gazeta do Povo obteve em 2012 uma média de circulação de 42.786 exemplares por dia, sendo $01^{\circ}$ lugar do Paraná em jornais de circulação paga, por ano, e o $24^{\circ}$ do Brasil.

4 Coleta de dados realizada pelo Núcleo de Pesquisa em Comunicação Política \& Opinião Pública (CPOP-UFPR), da Universidade Federal do Paraná. 
Cobertura eleitoral e visibilidade dos candidatos no jornal Gazeta do Povo e as eleições de 2012 em Curitiba

a Gazeta do Povo deu cobertura ao tema de campanha eleitoral para prefeito de Curitiba em 2012 e qual a visibilidade no jornal dada aos candidatos. A partir dos dados quantitativos poderão ser identificados padrões de comportamento sobre o jornal pesquisado.

A visibilidade dos candidatos a prefeito em Curitiba, nas eleições de 2012, dado pelo jornal impresso Gazeta do Povo foi distribuída de certa forma correspondente às preferências dos eleitores demonstradas nas pesquisas eleitorais de intenção de voto. Pois os candidatos Gustavo Fruet (PDT) e Ratinho Junior (PSC) foram os que avançaram ao segundo turno nas eleições e também foram os que tiveram maior visibilidade no período eleitoral, com 465 entradas (citações ou fotos/imagens nos textos das matérias) para Fruet e 438 para Ratinho Junior, como apresenta a Tabela 1.

\begin{tabular}{lcc}
\hline Candidato / Partido & Entradas $^{{ }^{1}}$ & $\%$ \\
\hline Gustavo Fruet (PDT) & 465 & 27,79 \\
\hline Ratinho Junior (PSC) & 438 & 26,18 \\
\hline Luciano Ducci (PSB) & 374 & 22,36 \\
\hline Rafael Greca (PMDB) & 217 & 12,97 \\
\hline Alzimara Bacelar (PPL) & 56 & 3,35 \\
\hline Avanilson Araújo (PSTU) & 50 & 2,99 \\
\hline Bruno Meirinho (PSOL) & 73 & 4,36 \\
\hline
\end{tabular}

Tabela 1 - Cobertura eleitoral de 2012 dos candidatos realizada pela Gazeta do Povo Fonte: Núcleo de Pesquisa em Comunicação Política \& Opinião Pública (CPOP-UFPR)

O número de entradas que indica a visibilidade dos candidatos na Tabela 1 demonstra que os candidatos Alzimara Bacelar (PPL), Avanilson Araújo (PSTU) e Bruno Meirinho (PSOL), que tinham baixa intenção de voto nas pesquisas eleitorais, também foram os menos citados na cobertura jornalística sobre as eleições. Os candidatos Luciano Ducci (PSB) e Rafael Gresca (PMDB) que protagonizaram na disputa eleitoral entre os quatro candidatos com maior preferência entre os eleitores tiveram 374 e 217 entradas respectivamente. O número de entradas de Ducci e de Greca ficou abaixo do número de entradas de Fruet e Ratinho Junior, pois os dois últimos foram os que avançaram ao segundo turno, então a cobertura jornalística continuou sobre os candidatos que permaneceram na disputa eleitoral. Todavia, Greca e Ducci ainda tiveram entradas na cobertura eleitoral após o dia da eleição 
de primeiro turno em 07 de outubro, até o final do segundo turno de 2012.

Consideramos pertinente também observar a visibilidade nos títulos das matérias5. Títulos, antetítulos e subtítulos, em conjunto, compõem a manchete, principal ou secundária, um lugar narrativo de onde se informa sobre o enredo da matéria: assunto, tema principal, pertinência e afinidades (BEZERRA, 2005, p. 52). Por meio desta variável podemos verificar não apenas os candidatos que tiveram mais citações no texto, mas os que o jornal proporcionou mais destaque com aparição nos títulos das matérias.

A distribuição de citações aos candidatos nos títulos das matérias seguiu o padrão esperado de maior cobertura aos líderes das pesquisas eleitorais. Conforme a Tabela 2 observamos que os candidatos Fruet e Ratinho que avançaram ao segundo turno tiveram citações nos títulos muito similar e muito equilibrado quantitativamente. Isso demonstra que a Gazeta do Povo adotou um critério de cobertura eleitoral, ao menos em citações, não considerando os enquadramentos sobre cada candidato.

\begin{tabular}{lcc}
\multicolumn{1}{c}{ Candidato } & Entradas & \% \\
\hline Gustavo Fruet(PDT) & 180 & 17,24 \\
Ratinho Junior(PSC) & 184 & 17,62 \\
Luciano Ducci(PSB) & 113 & 10,82 \\
Rafael Greca (PMDB) & 53 & 5,08 \\
Alzimara Bacelar(PPL) & 13 & 1,25 \\
Avanilson Araújo(PSTU) & 10 & 0,96 \\
Bruno Meirinho(PSOL) & 14 & 1,34 \\
\hline
\end{tabular}

Tabela 2 - Visibilidade dos candidatos nos títulos das matérias na cobertura eleitoral de 2012 realizada pela Gazeta do Povo

Fonte: Núcleo de Pesquisa em Comunicação Política e Opinião Pública (CPOP/UFPR)

Para ilustrar esta cobertura e visibilidade faremos uma comparação por volume de citações no decorrer do período eleitoral com os candidatos Gustavo Fruet, Ratinho Junior, Luciano Ducci e Rafael Greca, pois foram os que tiveram maior destaque na cobertura eleitoral da Gazeta do Povo, conforme 
Cobertura eleitoral e visibilidade dos candidatos no jornal Gazeta do Povo e as eleições de 2012 em Curitiba

os gráficos a seguir. ${ }^{6}$

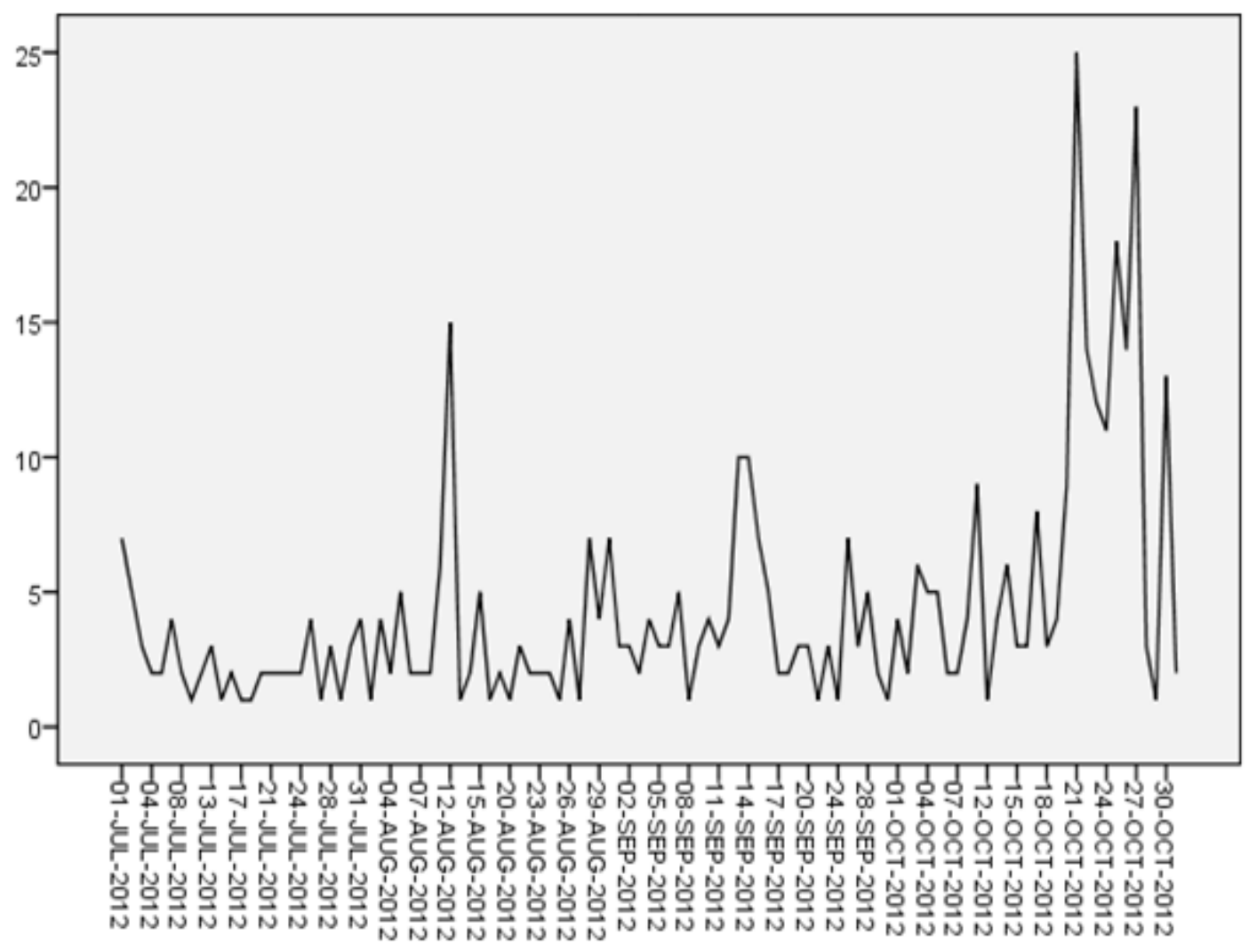

Figura 1 - Gráfico de visibilidade de Gustavo Fruet (PDT) durante o período eleitoral na Gazeta do Povo por número de citações diárias

Fonte: Núcleo de Pesquisa em Comunicação Política \& Opinião Pública (CPOP-UFPR)

A cobertura da Gazeta do Povo sobre o candidato Gustavo Fruet manteve uma constância no jornal durante o período eleitoral, mas é possível analisar pelo Gráfico 1 que no final da campanha a visibilidade foi alta, uma vez que Fruet foi um dos candidatos que disputaram o segundo turno da eleição de 2012 para prefeito de Curitiba. O adversário de Fruet na disputa foi Ratinho Junior, que apresenta uma visibilidade semelhante a qual foi apresentada no Gráfico 1, por Gustavo Fruet, conforme demonstra o Gráfico 2. É possível constatar na comparação da visibilidade de Fruet e de Ratinho pelos gráficos, que houve períodos em que o jornal deu mais visibilidade para ambos os candidatos e que a cobertura no final do período eleitoral, mais precisamente próximo a decisão do segundo turno, nos últimos dias de outubro, há um aumento considerável de cobertura jornalística sobre as

6 A disposição dos gráficos tem no eixo X(horizontal) a linha temporal, que corresponde ao período eleitoral e o eixo Y (vertical) ao número de citações dos candidatos por dia. 
eleições, no que envolve a decisão do pleito para os candidatos. É possível identificar também na comparação entres os gráficos 1 e 2 a visibilidade de Fruet e Ratinho Junior, após a decisão de segundo turno. Verifica-se que Fruet teve mais visibilidade (por volume de citações) que Ratinho, visto que os resultados da eleição corroboraram com os resultados das pesquisas eleitorais.

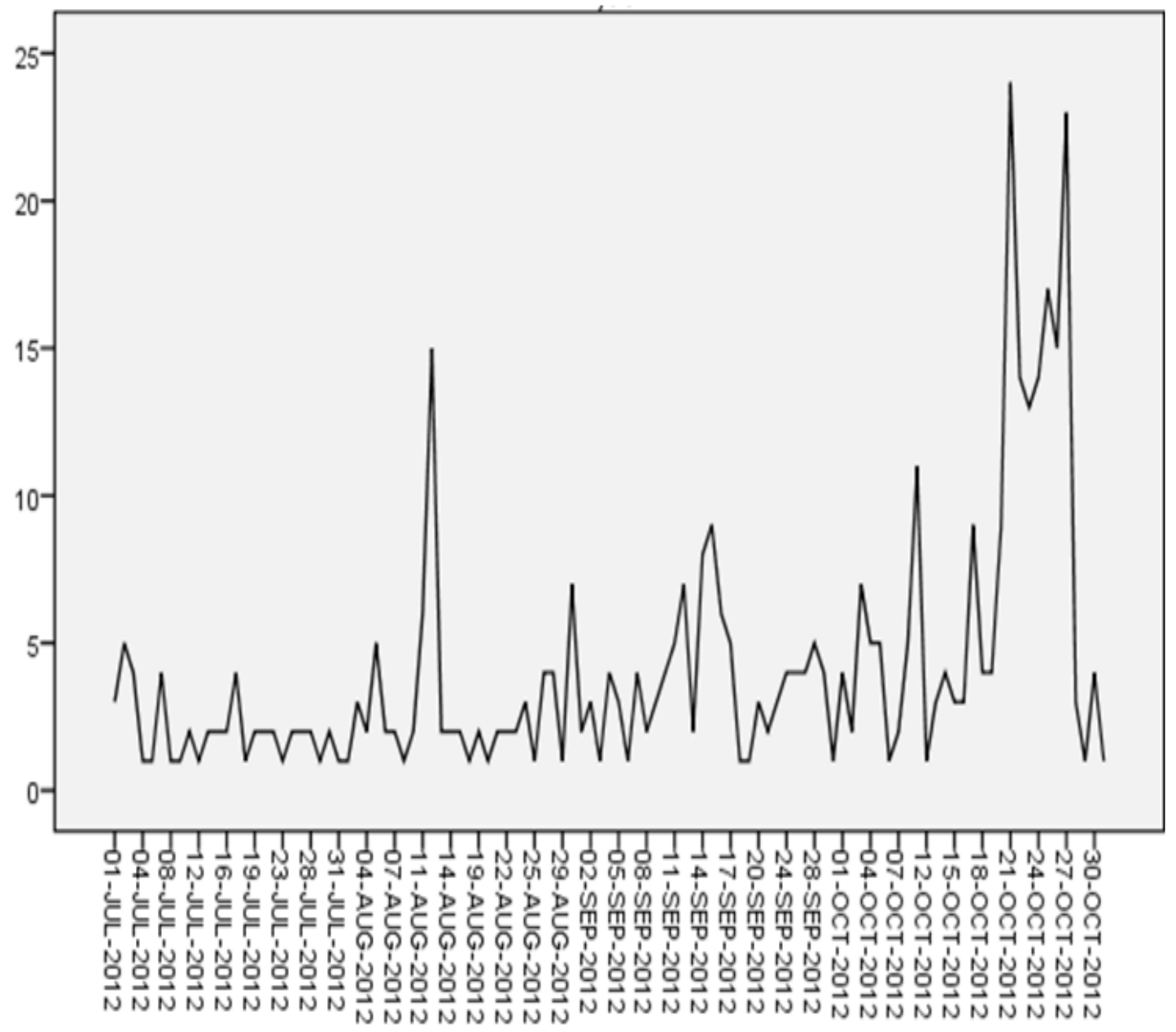

Figura 2 - Gráfico de visibilidade de Ratinho Junior (PSC) durante o período eleitoral na Gazeta do Povo por número de citações diárias

Fonte: Núcleo de Pesquisa em Comunicação Política \& Opinião Pública (CPOP-UFPR)

A visibilidade da cobertura sobre o candidato Luciano Ducci, do PSB, no jornal impresso Gazeta do Povo foi similar à cobertura de Gustavo Fruet e Ratinho Junior, conforme demonstra o Gráfico 3 em comparação aos Gráfi$\cos 1$ e 2. Todavia, esta semelhança é observada do período de $1^{\circ}$ de julho até a decisão do primeiro turno em 7 de outubro. Uma vez que Ducci não avançou para o segundo turno a cobertura jornalística diminuiu, mas continuou constante durante o mês de outubro, pois Luciano Ducci era o atual prefeito 
Cobertura eleitoral e visibilidade dos candidatos no jornal Gazeta do Povo e as eleições de 2012 em Curitiba

com mandato até o final de 2012. Ou seja, apesar de sair da disputa eleitoral Luciano Ducci, por ter o cargo de prefeito, permaneceu como tema para cobertura jornalística da agenda pública e governamental 7 .

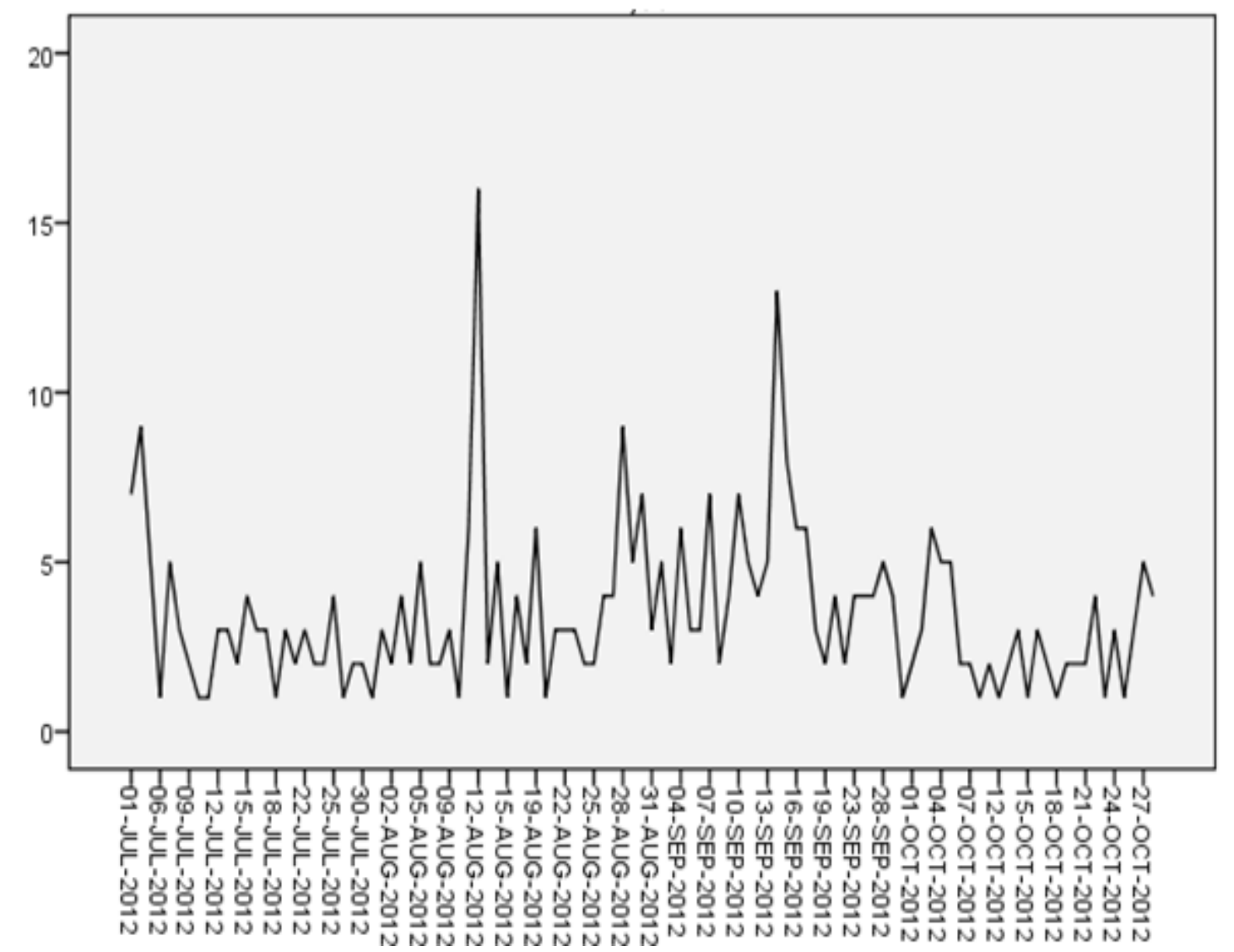

Figura 3 - Gráfico de visibilidade de Luciano Ducci (PSB) durante o período eleitoral na Gazeta do Povo por número de citações diárias

Fonte: Núcleo de Pesquisa em Comunicação Política \& Opinião Pública (CPOP-UFPR)

Com relação ao candidato Rafael Greca a visibilidade apresentada foi semelhante à de Luciano Ducci (comparar Gráfico 3 e Gráfico 4), tendo cobertura no primeiro e no segundo turno, com pouca visibilidade mas constante,

7 Pesquisadores norte-americanos de comunicação investigaram os efeitos dos meios de comunicação, comparando-se ao longo de um período de tempo, as questões destacadas pelos meios de comunicação com os processos sociais refletidos nas estatísticas e as opiniões da população sobre a tarefa política mais premente, eles descobriram que os meios utilizados para ir à frente dos outros dois fenômenos. Parece, portanto, que aqueles que levantam questões e colocá-los sobre a mesa. Os pesquisadores americanos inventaram para descrever este processo, a expressão agenda-setting function [função de estabelecimento de ordem do dia] (NOELLE-NEUMANN, 1995, p. 137). Com base nos autores destes estudos Paulo Liedtke (2007, p. 3) expõe a seguinte classificação entre agendas: 1- agenda midiática (media agenda-setting), estudos dos conteúdos da mídia; 2- agenda pública (public agenda-setting), estudos que conceituam a relativa importância dos fatos por parte dos membros do público; e 3- agenda governamental (policy 
apesar de ter sido o $4^{\circ}$ lugar nas preferências de intenção de voto pelos eleitores, com percentual de intenção de voto de $10 \%$ em julho e em outubro de 2012. O número de entradas de Greca na cobertura eleitoral também foi o $4^{\circ}$ lugar com 217 entradas, logo abaixo de Luciano Ducci com 374 entradas, conforme a Tabela 1. Rafael Greca, assim como Ducci, é ex-prefeito de Curitiba, então pressupõe-se um certo prestígio público para a continuidade da cobertura jornalística sobre o candidato.

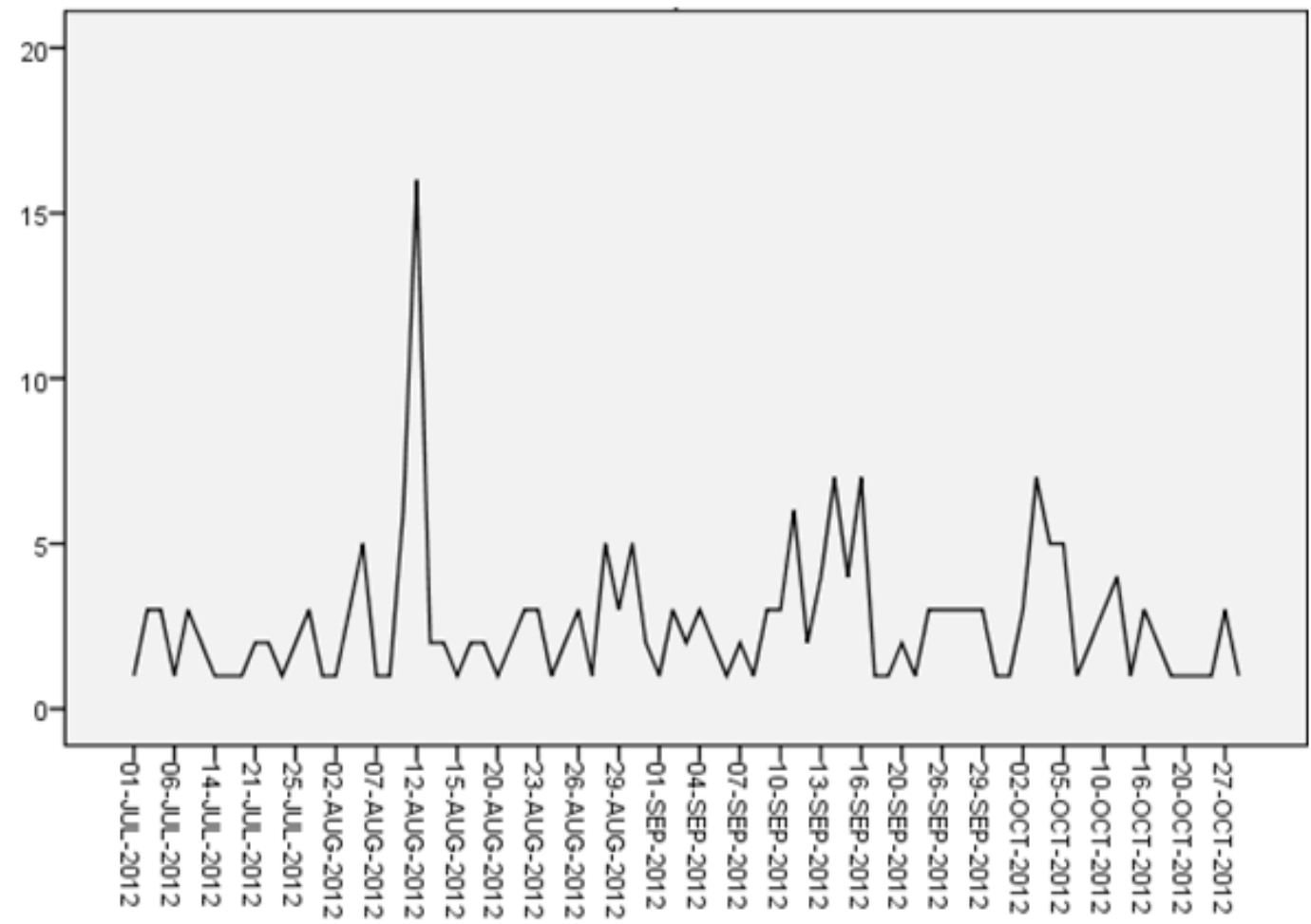

Figura 4 - Gráfico de visibilidade de Rafael Greca (PMDB) durante o período eleitoral na Gazeta do Povo por número de citações diárias

Fonte: Núcleo de Pesquisa em Comunicação Política \& Opinião Pública (CPOP-UFPR)

O volume de citações é uma variável importante para mensurar qual o padrão de cobertura que o jornal Gazeta do Povo proporcionou aos candidatos no período eleitoral. Todavia, quando analisamos qual a atribuição que os candidatos recebem pelo jornal podemos identificar diferenças significativas na cobertura. Conforme o Quadro 1 observamos que o candidato Fruet esteve presente em das entradas (matérias) 58,91 e Ratinho Junior em $54,98 \%$. É relativamente equilibrada esta cobertura da Gazeta do Povo, no entanto observamos uma significativa diferença de atribuição de visibi-

8 O percentual somado dos candidatos é superior a 100\%, pois as matérias podem citar apenas um candidato, ou todos os candidatos em uma única matéria. 
Cobertura eleitoral e visibilidade dos candidatos no jornal Gazeta do Povo e as eleições de 2012 em Curitiba

lidade positiva e negativa entre os dois candidatos. Gustavo Fruet recebeu maior percentual de visibilidade positiva $12,74 \%$, enquanto que Ratinho Junior recebeu $9,87 \%$. E Fruet recebeu um menor percentual de visibilidade negativa com $5,65 \%$ e Ratinho recebeu $6,70 \%$ de visibilidade negativa. Importante destacar também que o candidato Luciano Ducci concorria a reeleição à prefeitura e foi o único candidato entre os quatro líderes das pesquisas eleitorais a receber uma atribuição de valência negativa superior à positiva na visibilidade. Pois Ducci recebeu $8,24 \%$ de valência negativa e apenas $6,90 \%$ de valência positiva na visibilidade da cobertura eleitoral proporcionada pela Gazeta do Povo.

\begin{tabular}{|l|l|r|l|l|l|}
\hline \multicolumn{2}{|c|}{ Valência } & $\begin{array}{l}\text { Gustavo Fruet } \\
\text { (PDT) }\end{array}$ & $\begin{array}{l}\text { Ratinho Junior } \\
(\mathrm{PSC})\end{array}$ & $\begin{array}{l}\text { Luciano } \\
\text { Ducci(PSB) }\end{array}$ & $\begin{array}{l}\text { Rafael Greca } \\
(\mathrm{PMDB})\end{array}$ \\
\hline \multirow{5}{*}{ Frequência } & Positiva & 133 & 103 & 72 & 60 \\
\cline { 2 - 6 } & Percentual & $12,74 \%$ & $9,87 \%$ & $6,90 \%$ & $5,75 \%$ \\
\cline { 2 - 6 } & Negativa & 59 & 70 & 86 & 21 \\
\cline { 2 - 7 } & Percentual & $5,65 \%$ & $6,70 \%$ & $8,24 \%$ & $2,01 \%$ \\
\cline { 2 - 7 } & Neutra & 397 & 378 & 319 & 211 \\
\cline { 2 - 7 } & Percentual & $38,03 \%$ & $36,21 \%$ & $30,56 \%$ & $20,21 \%$ \\
\cline { 2 - 7 } & Equilibrada & 26 & 23 & 22 & 7 \\
\cline { 2 - 6 } & Percentual & $2,49 \%$ & $2,20 \%$ & $2,11 \%$ & $0,67 \%$ \\
\cline { 2 - 6 } & Total & 615 & $\mathbf{5 7 4}$ & $\mathbf{4 9 9}$ & 299 \\
\cline { 2 - 6 } & Percentual & $58,91 \%$ & $54,98 \%$ & $47,81 \%$ & $28,64 \%$ \\
\hline
\end{tabular}

Quadro 1 - Visibilidade e valência para as candidaturas na Gazeta do Povo durante o período eleitoral de 2012

Fonte: Núcleo de Pesquisa em Comunicação Política e Opinião Pública (CPOP/UFPR)

Com relação aos candidatos Bruno Meirinho (PSOL), Alzimara Bacellar (PPL) e Avanilson Araújo (PSTU) estes não foram mais citados após a eleição do primeiro turno, em 7 de outubro. Como demonstramos neste trabalho estes candidatos não se destacaram nas pesquisas eleitorais, consequentemente tiveram pouca visibilidade no primeiro turno, conforme demonstra-se na Tabela 1, e nenhuma visibilidade no segundo turno. No entanto o percentual de visibilidades destes candidatos foi até acima do percentual 
de intenção de voto obtido durante o período eleitoral. Pois nas pesquisas de intenção de voto os candidatos atingiram no máximo 1\% da preferência dos eleitores, enquanto que no percentual de entradas no jornal Bruno Meirinho (PSOL) obteve 4,36\% de visibilidade, Alzimara Bacellar (PPL) 3,35\% e Avanilson Araújo (PSTU) 2,99\%.

\section{CONSIDERAÇÕES FINAIS}

Este trabalho teve a proposta de identificar a visibilidade na linha do tempo do período eleitoral, no jornal Gazeta do Povo, dos candidatos a prefeito de Curitiba nas Eleições 2012 e comparar esta com os resultados das pesquisas de intenção de voto para verificar qual a relação destas duas variáveis durante o período eleitoral. Também verificamos a atribuição da visibilidade aos principais candidatos.

Como hipótese inicial em que os resultados das pesquisas de intenção de voto podem refletir na visibilidade dos candidatos no jornal, considerando as pesquisas de intenção de voto como variável independente e a visibilidade no jornal como variável dependente, identificou-se que os candidatos com maior percentual de intenção de voto também foram os com mais visibilidade no jornal. Foi possível, também, identificar um outro resultado, que o jornal dá maior visibilidade aos candidatos nos últimos dias de campanha eleitoral, no caso de 2012 um período correspondente a semana da decisão do $2^{\circ}$ turno.

Pode-se constatar uma outra característica do jornal Gazeta do Povo na cobertura eleitoral de 2012, que o jornal mantém um padrão equilibrado de visibilidade aos candidatos, com resultados significativos nas pesquisas de intenção de voto. Pois a cobertura eleitoral oferecida no $1^{\circ}$ turno é próxima em relação aos três candidatos líderes nas pesquisas, Ratinho, Ducci e Fruet e com menor intensidade para Rafael Greca. Então pelas evidências encontradas pode-se concluir que a visibilidade da cobertura eleitoral proporcionada pela Gazeta do Povo tem uma relação proporcional com a preferência dos eleitores nas pesquisas de intenção de voto. Todavia a Gazeta do Povo adota diferentes critérios na valência positiva e negativa para os candidatos. Estes critérios foram observados na comparação entre Fruet, Ratinho e Ducci, em que o primeiro prevaleceu em visibilidade positiva e os dois últimos em visibilidade negativa. Embora os percentuais sejam próximos são pertinentes para a diferenciação e para observar o critério de pa- 
Cobertura eleitoral e visibilidade dos candidatos no jornal Gazeta do Povo e as eleições de 2012 em Curitiba

drão de cobertura que a Gazeta do Povo adotou.

Então, presume-se que o jornal ao propiciar visibilidade aos candidatos com maior interesse pelos eleitores considera estes candidatos como parte dos temas mais pertinentes para divulgação de informações sobre a campanha eleitoral. Com isso aponta-se a pesquisa eleitoral como uma ferramenta essencial para o período de campanha eleitoral e para os meios de comunicação, levando em conta que a cobertura eleitoral também é realizada pela TV, rádio e internet, além da própria mídia impressa. Por este motivo também os meios de comunicação contratam pesquisas de opinião para poder depois divulgá-las. 


\section{REFERÊNCIAS}

ALDÉ, Alessandra; MENDES, Gabriel; FIGUEIREDO, Marcus. Tomando Partido: Imprensa e eleições presidenciais em 2006. In: Compós UTP - $16 .^{\circ}$ Encontro Anual da Associação Nacional dos Programas de Pós-Graduação em Comunicação na Universidade Tuiuti do Paraná. Anais da XVI Compós. Curitiba, $2007 a$.

ALDÉ, Alessandra; MENDES, Gabriel Gutierrez; FIGUEIREDO, Marcus. Imprensa e eleições presidenciais: natureza e conseqüências da cobertura das eleições de 2002 e 2006. In: LIMA, Venício A. de. (Org.). A mídia e as eleições de 2006. São Paulo: Fundação Perseu Abramo, 2007b, v. 1, p. 65-87.

ASSOCIAÇÃO NACIONAL DE JORNAIS. Maiores jornais do Brasil. Disponível em: <http:// www.anj.org.br/a-industria-jornalistica/jornais-no-brasil/maiores-jornais-do-brasil>. Acesso em 14 abr. 2013.

BABBIE, Earl. Métodos de Pesquisa de Survey. Belo Horizonte: Ed. UFMG, 2005.

BAUER, Martin W. Análise de conteúdo clássica: uma revisão. In: BAUER, M. \& GASKEL, G. Pesquisa qualitativa com texto, imagem e som. Petrópolis: Vozes, 2003.

BEZERRA, Heloisa Dias. Cobertura Jornalística e Eleições Majoritárias: Proposta de um Modelo Analítico. 341 f. Tese (Doutorado em Ciência Política) - Instituto Universitário de Pesquisa do Rio de Janeiro, Rio de Janeiro, 2005.

BIROLI, Flávia; MIGUEL, Luis Felipe; MOTA, Fernando Ferreira. Mídia, eleições e pesquisa de opinião no Brasil (1989-2010): um mapeamento da presença das pesquisas na cobertura eleitoral. In: Revista Compolítica, n. 1, vol. 1, ed. março-abril. Rio de Janeiro: Compolítica, 2011.

BISQUERRA ALZINA, Rafael; SARRIERA, Jorge Castellá; MARTíNEZ, Francesc. Introdução à estatística: enfoque informático com o pacote estatístico SPSS. Porto Alegre: Artmed, 2004.

BRASIL. Presidência da República. Secretaria de Comunicação Social. Pesquisa brasileira de mídia 2014: hábitos de consumo de mídia pela população brasileira. Brasília: Secom, 2014.

DATAFOLHA - Instituto de Pesquisas. Intenção de voto para prefeito de Curitiba - 19 e 20 de julho de 2012. Disponível em: <http://datafolha.folha.uol.com.br/po/ver_po.php?session=1209>. Acesso em 14 abr. 2013.

DATAFOLHA - Instituto de Pesquisas. Intenção de voto para prefeito de Curitiba - 02 e 03 de outubro de 2012. Disponível em: <http://datafolha.folha.uol.com.br/po/ver_ po.php?session=1256 >. Acesso em 14 abr. 2013.

DATAFOLHA - Instituto de Pesquisas. Intenção de voto para prefeito de Curitiba - 17 e 18 de outubro de 2012. Disponível em: <http://datafolha.folha.uol.com.br/po/ver_po.php?session=1264 > Acesso em 14 abr. 2013.

DOXA - Laboratório de Pesquisa em Comunicação Política e Opinião Pública. Eleições 2008. Rio de Janeiro, RJ: 2008.

HEDLER, Ana Paula; GADINI, Sérgio Luiz; CERVI, Emerson Urizzi. A cobertura jornalística 
Cobertura eleitoral e visibilidade dos candidatos no jornal Gazeta do Povo e as eleições de 2012 em Curitiba

no período eleitoral: uma análise a partir das eleições 2008 no interior do Paraná. Século XXI, UFSM, Santa Maria: Revista de Ciências Sociais, v. 1, n. 2, 2011, p. 79-94.

KUNTZ. Ronald. A. Manual de campanha eleitoral: marketing político. $8^{\text {a }}$ ed.- São Paulo: Global, 2000.

LIEDTKE, Paulo Fernando. Governando com a mídia: o agendamento mútuo entre o Estado e o mass media na política nacional. In: Compós UTP - $16 .^{\circ}$ Encontro Anual da Associação Nacional dos Programas de Pós-Graduação em Comunicação na Universidade Tuiuti do Paraná. Anais da XVI Compós. Curitiba, 2007. Disponível em <http://www.compos. org.br/data/biblioteca_40.pdf>. Acesso em 04 mai. 2013.

LINHARES, Bianca de Freitas; ALVES, Douglas Santos. Metodologia de ensino em pesquisa social quantitativa. Pensamento Plural, Pelotas, v. 7, n. 14, p.23-39, 2014. Disponível em: <http://periodicos.ufpel.edu.br/ojs2/index.php/pensamentoplural/article/view/3782>. Acesso em 15 nov. 2015.

McCOMBS, Maxwell. A Teoria da Agenda: a mídia e a opinião pública. Petrópolis, RJ: Vozes, 2009.

MENDES, Antonio Manuel Teixeira. O papel das pesquisas eleitorais. Novos Estudos, CEBRAP, n. 29, p. 28-33, 1991.

NOELLE-NEUMANN, Elisabeth. La espiral del silencio - Opinião pública: nuestra piel social. Barcelona: Paidós, 1995.

PUTNAM, Robert; LEONARDI, Robert; NANETTI, Raffaella. Comunidade e democracia: a experiência da Itália moderna. $5^{\mathrm{a}}$ ed., Rio de Janeiro: FGV, 2009.

QUADROS, Doacir Gonçalves; SANTOS, Romer Mottinha; MORAES, Thiago Perez Bernardes; RIBIERSKI, Audrilise Alissandri; MAIA, Elisangela Rocha. Mídia Impressa e Eleições 2010: uma análise parcial da cobertura do jornal O Estado do Paraná. Curitiba, PR: Intersaberes, 2010.

RODRIGO ALSINA, Miquel. A construção da notícia. Petrópolis: Vozes, 2009.

RODRIGUES, Malena Rehbein. Imprensa e Congresso ou Como a Mídia pauta a Política. Brasília, DF: Câmara dos Deputados, Coordenação de Publicações, 2002.

ROTHBERG, Danilo. Jornalismo público: informação, cidadania e televisão. São Paulo: Editora Unesp, 2011.

RUBIM, Antonio Albino Canelas. Comunicação e política. São Paulo: Hacker, 2000.

SILVA, Heber Ricardo. A democracia impressa: transição do campo jornalístico e do político e a cassação do PCB nas páginas da grande imprensa, 1945-1948 [online]. São Paulo: Editora UNESP; São Paulo: Cultura Acadêmica, 2009. 240 p.

SOMMA NETO, João. Show e poder no telejornalismo. In: SOMMA NETO, João (Org.); ANDRE, Hendryo (Org.); OUTROS (Org.). Mídia e política: caminhos cruzados. 01. ed. Curitiba: Programa de Pós-Graduação em Comunicação e Sociedade da UFPR, 2011. v. 01. p. 11-30.

TRIBUNAL REGIONAL ELEITORAL. Assessoria de Comunicação Social do TRE-PR. Curitiba, PR, 2012. Disponível em <http://www.tse.jus.br/noticias-tse/2012/Agosto/corte-do-tre- 
-pr-mantem-indeferimento-do-registro-de-carlos-moraes/?searchterm=carlos\%20moraes >. Acesso em 03 de mai. 2013.

\section{Romer Mottinha Santos}

Mestre em Ciência Política pela Universidade Federal do Paraná. Bacharel em Ciência Política pelo Centro Universitário Internacional Uninter. Pesquisador do Grupo de Pesquisas Comunicação e Elites (Uninter) e do Núcleo de Pesquisa em Comunicação Política e Opinião Pública (UFPR).

RECEBIDO EM: 26/04/2015

APROVADO PARA PUBLICAÇÃO: 06/10/2015 